\title{
Spark plasma sintering of graphene reinforced hydroxyapatite composites
}

Szilvia Klébert a*, Csaba Balázsi b, Katalin Balázsi c Eszter Bódis a, Péter Fazekas a, Anna Mária Keszler a, János Szépvölgyi a, Zoltán Károly a

a Institute of Materials and Environmental Chemistry, Research Centre for Natural Sciences HAS

b Institute for Materials Science and Technology, Bay Zoltán Nonprofit Ltd. for Applied Research, Fehérvári str. 130, 1116 Budapest, Hungary

c Institute for Technical Physics and Materials science, Research Centre for Natural Sciences, Hungarian Academy of Sciences, Konkoly-Thege M. str 29-33, 1121 Budapest, Hungary

\begin{abstract}
Hydroxyapatite / graphene (HAP/GNPs) composites were prepared by spark plasma sintering (SPS). Sintering was carried out at various temperatures $\left(700^{\circ} \mathrm{C}\right.$ and $\left.900^{\circ} \mathrm{C}\right)$ and holding times $(5$ and 10 min). Mechanical and structural properties were studied. The highest relative density $\sim 96 \%$ was obtained at $700^{\circ} \mathrm{C}$ sintering temperature independently on holding time. Composite with highest mechanical properties (hardness $\sim 4 \mathrm{GPa}$, 3-point bending strength $\sim 119 \mathrm{MPa}$ ) consisted of HAP elongated grains with average length of $300 \mathrm{~nm}$. The GNPs were agglomerated and located on grain boundaries closed to porosities. The structural observation confirmed increased fraction of hexagonal shaped grains, and poorer mechanical properties with increased sintering time and temperature.
\end{abstract}

Keywords: SPS, Hydroxyapatite, graphene, composite, hardness 


\section{Introduction}

Implant biomaterials brought into direct contact with body tissue without any intermediate layer. Biomaterials may be divided into three main groups; plastics, metals or alloys and ceramics $[1,2]$. The most promising bioceramic material is a hydroxyapatite (HAP, Ca10(PO4)6(OH)2). It is a most used implant for tissue implantation due to its similarity with apatite in human skeletal system, bone and teeth in terms of the chemical composition ( $\mathrm{Ca} / \mathrm{P}$ ratio of 1.67$)$ and crystal structure [3]. HAP in different forms (powder, fiber, sintered) exhibited the excellent biocompatibility [4,5]. Sintered HAP may be an ideal candidate for orthopaedic and dental implants. The sintered HAP body showed lower mechanical properties as poor fatigue resistance, low toughness and flexural strength, which restrict its use as a major load bearing parts in the body [6]. M oreover, its chemical stability is limited to tri-and tetracalcium phosphates when exposed to prolonged heat during processing [7-9]. One of route to increasing the poor mechanical properties of sintered HAP is a development of nanosized $\operatorname{HAP}[10,11]$. The nanosized HAP can improve the sintering kinetics due to higher surface area and hence improved mechanical properties [12]. Other possible ways to overcome these mechanical limitations include the incorporation of a second reinforcement phase in the HAP matrix and lowering the sintering temperature to avoid chemical decomposition. Among reinforcing fillers glass, alumina, or various carbon nanosturctures, such as carbon nanotubes or graphene nanoplatelets have been investigated [13-17]. Graphene nanoplatelets (GNPs) formed by several layers of graphene with a thickness of up to $50 \mathrm{~nm}$ [18]. The superior properties of graphene or GNPs have already been utilized as filler additive to polymers [19-21] or ceramics [22]. So far only a few reports have been published on the use of graphene additive to improve the mechanical properties of hydroxyapatite ceramics [23]. Zhao et al. [24] prepared graphene platelet/biphasic calcium phosphate composites by hot pressing. He reported a considerable improvement in terms of mechanical properties like bending strength and fracture toughness using $1.5 \mathrm{wt} \%$ GNPs.

Contrary to other traditional sintering techniques in SPS the sample is directly heated by the applied electric current which results in quite fast and effective heating $[25,26]$. Even though the precise mechanism of sintering by pulsed electric current has not been clearly understood yet, its beneficial features are undeniable. This includes the clean interphases, the restricted grain growth because of lower temperature and shorter holding time, which eventually allows the production of nanostructured ceramics [27]. In this work, graphene nanoplatelets were used for reinforcing nanosized HAP and the densification processes were carried out by SPS method. The structural and mechanical properties of the HAP / GNPs composites have been studied. The effects of applied sintering temperature $\left(700^{\circ} \mathrm{C}, 900^{\circ} \mathrm{C}\right)$ and holding time $(5 \mathrm{~min}, 10 \mathrm{~min})$ on the mechanical properties and the structure of the composites are discussed. 


\section{Experimental Procedure}

Starting mixture

The starting powders used in these experiments were HAP powder and graphene. HAP preparation from eggshell and ortophosphoric acid in the laboratory was described earlier [28]. The as-prepared HAP powder is of $66 \mathrm{~nm}$ in size. The mean size was calculated from the measured specific surface area (29 m2* $\mathrm{g}-1$ ) of the HAP powder by 7 point BET method using Autosorb 1C apparatus. However, because of the high surface activity, HAP grains formed 5-20 $\mu \mathrm{m}$ size agglomerates. Multilayer graphene (MLG) or graphene nanoplatelets (GNPs) was prepared by milling synthetic graphite (Aldrich) in ethanol using a highly efficient attritor mill (Union Process, type 01-HD/HDDM) equipped with zirconia agitator delta discs and zirconia grinding media in a $750 \mathrm{ml}$ silicon nitride tank. The milling process has been performed with high rotation speed, $4000 \mathrm{rpm}$ until $10 \mathrm{~h}$. The milled product was dried and sieved with a filter with a mesh size of 325 . According to analysis the mean thickness of the crystallites was $13.7 \mathrm{~nm}$, which is equivalent to 40 graphene layers [29-30]. HAP powder and GNPs were mixed in a 98 to 2 wt\% ratio and milled in a high efficient attritor mill equipped with zirconia agitator discs, zirconia grinding balls and zirconia tank (750 mL). This milling process has been performed in ethanol with high rotation speed $(4000 \mathrm{rpm})$ for 2 hours, then the slurry was dried and sieved.

\section{Sintering}

The as-obtained mixtures were then sintered to discs of $3 \mathrm{~cm}$ in diameter and $5 \mathrm{~mm}$ in thickness by spark plasma sintering machine (HD P5, FCT GmbH). Composites with different sintering temperatures $\left(700^{\circ} \mathrm{C}\right.$ and $900^{\circ} \mathrm{C}$ ) and holding times ( 5 and 10 minute) were prepared (Table 1.) The heating rate was $100^{\circ} \mathrm{C} / \mathrm{min}$ up to $700^{\circ} \mathrm{C}$ and from 700 to $900^{\circ} \mathrm{C}$ it was decreased to $50^{\circ} \mathrm{C} / \mathrm{min}$ for fearing of abrupt gas accumulation. Temperature was continuously measured by thermocouples inserted to the graphite die. A chamber pressure of 1 mbar was maintained during consolidation. The powders were uniaxialy compressed throughout the sintering process with $50 \mathrm{MPa}$. Linear shrinkage of the powder compacts was monitored on line by measuring the relative displacement of the graphite punch.

\section{Analytical techniques}

Densities of sintered bodies were measured using Archimedes' principle immersion method, both apparent and bulk densities were determined. Theoretical density was calculated from data of 
starting materials (for HAP: $3.16 \mathrm{~g} / \mathrm{cm} 3$, for GNPs: $2.25 \mathrm{~g} / \mathrm{cm} 3$ [31]). X-ray diffraction (XRD) measurements were performed on a Siemens D5000 diffractometer using CuKal radiation. Diffractograms were obtained in a step scanning mode $20^{\circ} \leq 2 \theta \leq 65^{\circ}$. Three point bending strength measurements were carried out by AMMRC 85-21 standard procedure (U.S. army standard test method for flexural strength of high performance ceramics at ambient temperature) using an INSTRON 5966 instrument on rectangular specimens with dimensions of $28 \mathrm{~mm} \times 5 \mathrm{~mm} \times 2.5 \mathrm{~mm}$. Each specimen was grounded and the edges were chamfered. The obtained value represents the results of three parallel measurements. Microhardness of composites was measured after polishing by Leitz M iniload 2 microhardness tester with an applied load of $4.903 \mathrm{~N}$ and a holding time of $27 \mathrm{~s}$. The morphology of synthesized bodies was characterized by scanning electron microscopy (SEM, Zeiss type DSM 982 GEM INI with a heated field emission tungsten cathode).

\begin{tabular}{|c|c|c|c|c|c|}
\hline \multirow[b]{2}{*}{ Sample } & \multirow{2}{*}{$\begin{array}{l}\text { HAP } \\
w t \%\end{array}$} & \multirow{2}{*}{$\begin{array}{l}\text { GNPs } \\
\text { wt } \%\end{array}$} & \multicolumn{3}{|c|}{ SPS condition } \\
\hline & & & $\begin{array}{c}\text { Temperature } \\
{\left[{ }^{\circ} \mathrm{C}\right]}\end{array}$ & $\begin{array}{c}\text { Pressure } \\
\text { [MPa] }\end{array}$ & $\begin{array}{l}\text { Time } \\
\text { [min] }\end{array}$ \\
\hline HG-5-7 & \multirow{3}{*}{98} & \multirow{3}{*}{2} & 700 & \multirow{3}{*}{30} & \multirow{2}{*}{5} \\
\hline HG-5-9 & & & 900 & & \\
\hline $\begin{array}{l}\text { HG-10-7 } \\
\text { HG-10-9 }\end{array}$ & & & $\begin{array}{l}700 \\
900\end{array}$ & & 10 \\
\hline
\end{tabular}

Table 1. SPS conditions during HAP composites preparation.

Results and Discussion

Thermodynamic calculation

During sintering the HAP composites are exposed to high temperature so chemical reaction may also occur beside consolidation. As graphene layers were incorporated in the mixture and the die itself is made of graphite reduction may also take place between components. In order to predict the possible reactions thermodynamic calculation was carried out by code FACTSAGE, which determines the thermodynamically most stable phases and their relative amounts at a given temperature and pressure by Gibbs energy minimization. 
Figure 1. Chemical equilibrium diagram for the HAP/GNPs system assuming a 2:0.5 HAP:C molar ratio

The results of the theoretical calculations (Figure 1.) gave different values for the decomposition of HAP in the presence of carbon and without carbon. Decomposition of pure HAP occurs at around $1400^{\circ} \mathrm{C}$, which is in line with literature and is confirmed by thermogravimetric measurements [32]. In the presence of carbon decomposition temperature drops a little bit, however, HAP is chemically stable even up to $1000^{\circ} \mathrm{C}$. According to Cihlár [33] HAP decomposition takes place in two steps: first is at around $900{ }^{\circ} \mathrm{C}$ where the water leaves the system leading to oxyapatite, and the second one occurs at above $1300^{\circ} \mathrm{C}$ resulting in calcium phosphates and calcium oxide. Considerable development of $\mathrm{CO}, \mathrm{CO} 2$ and $\mathrm{H} 2$ gases is also expected, which might be also of interest in technical the point of view as sintering is carried out in a closed system. To avoid the undesirable formation of calcium phosphates, which impair the mechanical properties of HAP the SPS sintering experiments were performed temperature below $1000^{\circ} \mathrm{C}$, at $700^{\circ} \mathrm{C}$ and $900^{\circ} \mathrm{C}$, respectively.

\section{SPS}

Figure 2. The sintering curves on $700^{\circ} \mathrm{C}(\mathrm{a})$ and $900^{\circ} \mathrm{C}(\mathrm{b})$ in the function of time

Figures 2.a-b shows the sintering curves of the experiments conducted at 700 and $900^{\circ} \mathrm{C}$ for 10 minutes including the temperature, the shrinkage as well as the rate of shrinkage in the function of treatment time. From the latter curve it is apparent that sintering starts below the max sintering temperature at around $600^{\circ} \mathrm{C}$. The peaks under this temperature refer to the compaction on the effect of the increasing compression. The two peaks of the rate of shrinkage above $500^{\circ} \mathrm{C}$ on Figure 2.b is due to the change in the heating rate above $700^{\circ} \mathrm{C}$. In this way the rate slowed down than increased again at reaching the maximum temperature. Comparing the Figures show that the increased temperature gave rise to further shrinkage that implies to better consolidation. However, the prolonged sintering time from 5 to 10 minutes apparently does not result in further shrinkage.

On Figure 3 crystalline phases of the starting mixture and the sintered product are compared. The absence of calcium phosphates on the XRD pattern of the sintered body indicates that decomposition of HAP did not take place even at $900^{\circ} \mathrm{C}$. The presence of crystalline carbon in all XRD patterns, presumably in the form of graphene, confirms that carbon did not react with other oxide component. The characteristic peaks of $\mathrm{CaCO} 3$ could be detected in minor intensity in all samples. Even though $\mathrm{CaCO} 3$ is not stable above $860{ }^{\circ} \mathrm{C}$ at atmospheric pressure, probably due to the applied 
uniaxial pressure during SPS it did not decompose or at least not completely even at $900^{\circ} \mathrm{C}$. The main reason for the minor presence of $\mathrm{CaCO} 3$ in the starting mixture is the preparation method of HAP powder since it was synthesized from a biogenic material, eggshell as detailed in [34].

Figure 3. XRD patterns of the sintered bodies and the starting HAP powder

\begin{tabular}{|c|c|c|c|c|c|c|}
\hline \multirow[t]{2}{*}{ Sample } & \multicolumn{3}{|c|}{$\begin{array}{l}\text { Composition of the synthesized } \\
\text { powders (wt } \% \text { ) by XRD* }\end{array}$} & \multirow{2}{*}{$\begin{array}{c}\text { Relative } \\
\text { density } \\
\text { [\%] }\end{array}$} & \multirow{2}{*}{$\begin{array}{c}\mathrm{HV} \\
{[\mathrm{GPa}]}\end{array}$} & \multirow{2}{*}{$\begin{array}{c}3 \text { point bending } \\
\text { strength } \\
\text { [MPa] }\end{array}$} \\
\hline & HAP & $\mathrm{CaCO}_{3}$ & C & & & \\
\hline HG-5-7 & 92 & 6 & 2 & 95.65 & $4 \pm 0.5$ & $119 \pm 4.9$ \\
\hline HG-10-7 & 92 & 6 & 2 & 95.88 & $3.5 \pm 0.6$ & $100 \pm 4.8$ \\
\hline HG-5-9 & 94 & 4 & 2 & 89.12 & $2.2 \pm 0.4$ & $84 \pm 6.1$ \\
\hline HG-10-9 & 94 & 4 & 2 & 87.44 & $2 \pm 0.4$ & $91 \pm 5.2$ \\
\hline
\end{tabular}

Table 2. Characteristics and properties of the sintered samples

In Table 2. relative densities and other mechanical properties of particular tests obtained after sintering are listed. Density values show an interesting trend. Usually higher sintering temperature and longer sintering time are accompanied with higher density values. It could be anticipated also from the sintering curves, too. In contrast, samples prepared at $700{ }^{\circ} \mathrm{C}$ (HG-5-7 and HG-10-7) possess much higher theoretical density of ca. 96\% than samples (HG-5-9 and HG-10-9) heat treated at $900^{\circ} \mathrm{C}$. There are, however, only minor changes in the density values because of the prolonged holding time that is in accord to the sintering curves. The incomplete consolidation are usually attributed to pores remained inside the sample. Applying longer holding time some of the pores could be eliminated that explains the slightly higher density of the sample HG-5-10, although it was not high. Again, against our expectations the density of HG-9-10 decreased on longer heating. One reason of the remaining porosity could be the presence of graphene layers. Increased numbers of pores was reported for other graphene incorporated ceramic composites [35], too. It was mainly attributed to the clustering of the graphene layers. The higher amount of pores at the higher sintering temperature, however, implies other sources of pore formation that occurs with increasing temperature. This suggests the decomposition of $\mathrm{CaCO} 3$ at higher temperature that result in $\mathrm{CO} 2$. 
Alternatively, reaction may occur between the carbon and HAP. This is, however, should be excluded by the thermodynamics calculations. In addition, it is not confirmed by XRD results, either.

The relative densities and other mechanical properties of HAP samples obtained after sintering are listed in Table 2. Density values show an interesting trend. The higher relative densities were obtained in the case of $700^{\circ} \mathrm{C}$ sintering temperature compared with $900^{\circ} \mathrm{C}$. The sintering time did not have discernible effect to the mechanical properties. One reason of the remaining porosity could be the presence of graphene layers. Increased numbers of pores was reported for other graphene incorporated ceramic composites [35], too. It was mainly attributed to the clustering of the graphene layers. The higher amount of pores at the higher sintering temperature, however, implies other sources of pore formation that occurs with increasing temperature. This suggests the decomposition of $\mathrm{CaCO} 3$ at higher temperature that result in $\mathrm{CO} 2$. Alternatively, reaction may occur between the carbon and HAP. This fact should be excluded by the thermodynamics calculations. In addition, it is not confirmed by XRD results, either. Mechanical properties including hardness and bending strength follow a similar trend as relative density (Table 2.). Higher values were achieved applying lower sintering temperature. This tendency is probably also related to porosity of the HAP/graphene samples.

The influence of $2 \mathrm{wt} \%$ graphene addition to the mechanical changes was observed. The hardness of pure HAP sintered at $600^{\circ} \mathrm{C}$ showed $3.9 \pm 0.2 \mathrm{GPa}$ and 3 point bending strength was $58 \pm 5 \mathrm{M} \mathrm{Pa}$ from our previous work [36]. This fact proves that the addition of graphene may the positive effect of mechanical properties of composite. The SEM investigations of HAP/graphene composites were shown in Fig. 4.

Figure 4. SEM images of HAP/graphene composites sintered at different parameters. a) $700^{\circ} \mathrm{C}$ and 5 $\min$, b) $900^{\circ} \mathrm{C}$ and $\left.5 \mathrm{~min}, \mathrm{c}\right) 700^{\circ} \mathrm{C}$ and $10 \mathrm{~min}$, d) $900^{\circ} \mathrm{C}$ and $10 \mathrm{~min}$.

HAP / graphene composites sintered at lower sintering time (5 min) consisted of HAP elongated grains with average length of $300 \mathrm{~nm}$. The GNPs were agglomerated and located on grain bounderies closed to porosities (Fig. 4a). The increasing of sintering time caused the change of main part of grain's morphology from elongated to polycrystalline form. The average length of grains doubled. The few micrometer GNPs were located between HAP grains (Fig. 4b).

Increasing of sintering temperature from $700^{\circ} \mathrm{C}$ to $900^{\circ} \mathrm{C}$ resulted in morphological change and decreased HAP grain size. The average size of polygonal HAP grains was around $200-250 \mathrm{~nm}$. In this case, the $500 \mathrm{~nm}$ size GNPs were observed between HAP polygons (Fig. 4c). 
The $900^{\circ} \mathrm{C}$ and 10 min sintering time resulted in HAP crystals of $800 \mathrm{~nm}-1$ m length and $250 \mathrm{~nm}$ width. The GNPs plates were destructed to few tens nanometer size (Fig. 4d). Only in this case, no agglomeration of GNPs was observed.

The SEM observation confirmed increased fraction of hexagonal shaped grains with longer sintering time and higher temperature. Champion et al. claimed that grain growth during either pressureless sintering or SPS is significant only above $95 \%$ of theoretical density [25]. This fact also confirms that the lower values of theoretical density of the samples sintered at $900^{\circ} \mathrm{C}$ must be due to pores generated at that higher temperature probably by the decomposition of CaCO3. Nakahira et al. [37] and Watanabe et al. [38] showed that SPS at high temperatures leads to the selective growth of caxis of HAP crystals, resulting in coarse acicular grains that tend to lie in planes perpendicular to the direction of the applied compressive stress. Similar microstructure developed in silicon nitride ceramics during SPS, Shen Z. et al. [39] studied the formation of elongated grains and their effect on toughness. They concluded that the mechanism of grain growth during SPS, named 'dynamical ripening' is different from the Ostwald ripening.

\section{Conclusions}

In this work graphene nanoplatelet reinforced ( $2 \mathrm{wt} \%$ ) hydroxyapatite bioceramics were prepared by spark plasma sintering. Low sintering temperatures $\left(700\right.$ and $900{ }^{\circ} \mathrm{C}$ ) and short holding times $(5$ and $10 \mathrm{~min}$ ) were applied to avoid HAP decomposition and possible oxidation of the graphene platelets. The main findings were, as follows:

- $\quad$ SPS treatment of a HAP/2 wt\% GNPs composite proved to be superior in terms of mechanical properties over pure sintered HAP items.

- Best combination of the mechanical properties were obtained at as lower sintering temperature as $700{ }^{\circ} \mathrm{C}$ using 5 min sintering time with bending strength of $119 \mathrm{MPa}$ and hardness value of $4 \mathrm{GPa}$. These values decreased at higher sintering temperature $\left(900^{\circ} \mathrm{C}\right)$ due to the increased porosity, which can be attributed to the decomposition of the $\mathrm{CaCO} 3$ presented in minor amount in the starting powder as impurities.

- At higher sintering temperature the amount of the hexagonal shaped grains significantly increased, although their effect on the mechanical properties could not be noticed.

The authors believe that even better properties could be achieved using other, $\mathrm{CaCO} 3$ free HAP as starting material and improving the dispersion method of graphene to prevent its clustering in the matrix.

Acknowledgement 
The authors thanks to Dr. Gergely Gréta, Varga Viktor and Illés Levente from MTA TTK MFA Budapest for powder sample preparation and SEM investigation. The authors also kindly acknowledge the financial support of the National Office for Research and Technology (REG-KM -09-1-2009-0005) and also to OTKA grant No. 105355 projects.

\section{References}

[1] R.B. Heimann, Classic and Advanced Ceramics - From Fundamentals to Applications, (Wiley, Weinheim, 2010)

[2] Z. Li, M. Kawashita, J. Artif. Organs. 14,163 (2011)

[3] T. Kokubo, Bioceramics and their Clinical Applications (Woodhead publishing Ltd. Cambridge, 2008)

[4] S.V. Dorozhkin, Biomaterials 31, 1465 (2010)

[5] S. Kalmodia, S. Goenka, T. Laha, D. Lahiri, B. Basu, K. Balani, M ater. Sci. Eng. C, 26, 675 (2006)

[6] D. Bellucci, A. Sola, M. Gazzarri, F. Chiellini, V. Cannillo, M ater. Sci. Eng. C, 33, 1091 (2013)

[7] Y. Liu, Z. Shen, J. Eur. Ceram. Soc., 32, 2691 (2012)

[8] Y.W. Gu, N.H. Loh, K.A. Khor, S.B. Tor, P. Cheang, Biomaterials 23, 37 (2002)

[9] A.C. Tas, Biomaterials 21, 1429 (2000)

[10] W. Quea, K.A. Khor, J.L. Xu, L.G. Yu, J. Eur. Ceram. Soc. 28, 3083 (2008)

[11] D. Grossin, S. Rollin-Martinet, C. Estournès, F Rossignol, E. Champion, C. Combes, C. Rey, C Geoffroy, C Drouet, Acta Biomater. 6, 577 (2010)

[12] S. Bose, S.K. Saha, J. Am. Ceram. Soc. 86, 1055 (2003)

[13] W. Wang, Y. Zhu, F. Watari, S. Liao, A. Yokoyama, M. Omori, H. Ai, F. Cui, Appl. Surf. Sci. 262, 194 (2012)

[14] J.D. Santos, J.C. Knowles, R.L. Reis, F.J. Monteirof G.W. Hastings, Biomaterials 15, 5 (1994)

[15] Y. Zhang, S. Tan, Y. Yin, Ceram. Int., 29, 113 (2003)

[16] C. Kealley, M. Elcombe, A. Riessen, B. Ben-Nissan, Physica B 385-386, 496 (2006)

[17] H. Ji, P.M. M arquis, Biomaterials 13, 744 (1992)

[18] J. Dusza, J. M orgiel, A. Duszová, L. Kvetková, M. Nosko, P. Kun, Cs. Balázsi, J. Eur. Ceram. Soc. 32, 3389 (2012)

[19] S.A. Goldstein, J. Biomechanics 20, 1055 (1987)

[20] T. Kuilla, S. Bhadra, D. Yao, N.H. Kim, S. Bose, J.H. Lee, Prog. Polym. Sci. 35, 1350 (2010)

[21] J.R. Potts, D.R. Dreyer, Ch.W. Bielawski, R.S. Ruoff, Polym. 52, 5 (2011)

[22] A. Nieto, D. Lahiria A. Agarwal, Scr. M ater. 69, 678 (2013)

[23] J. Zhu, H.M. Wong, K.W.K. Yeung S.C. Tjong, Adv. Eng. Mater. 13, 336 (2011) 
[24] Y. Zhao, K. Sun, W.-L. Wang, Y.-X. Wang, X.-L. Sun, Y.-J. Liang, X.-N. Sun, P.-F. Chui. Cer. Int. 39, 7627 (2013)

[25] E. Champion, Acta Biomater. 9, 5855 (2013)

[26] D. Lahiri, V. Singh, A.K. Keshri, S. Seal, A. Agarwal, Carbon 48, 3103 (2010)

[27] W. Wang, Y. Zhu, F. Watari, S. Liao, A. Yokoyama, M. Omori, H. Ai, F. Cui, Appl. Surf. Sci. 262, 194 (2012)

[28] Cs. Balázsi, F. Wéber, Zs. Kövér, E. Horváth, Cs. Németh. Preparation of calcium-phosphate bioceramics from natural resources, Journal of the European Ceramic Society, Volume 27, Issues 2-3, 2007, Pages 1601-1606

[29] L. Kvetková, A. Duszová, M. Kasiarová, F. Dorcáková,J Dusza, Cs. Balázsi, J. Eur. Ceram. Soc. 33, 2299 (2013)

[30] P. Kun, F. Wéber, Cs. Balázsi. Cent. Eur. J. Chem. 9(1), 47 (2011)

[31] M.I. Kay, R.A. Young A.S. Posner, Nature 204, 1050 (1964)

[32] C.J. Liao, F.H. Lin, K.S. Chen, J.S. Sun, Biomaterials 20, 1807 (1999)

[33] J. Cihlár, A. Buchal, M. Trunec, J. Mat. Sci. 34, 6131 (1999)

[34] G. Gergely, F. Wéber, I. Lukács, L. Illés, A.L. Tóth et al., Cent. Eur. J. Chem. 8(2), 375 (2010)

[35] L. Kvetkova, A. Duszova, P. Hvizdos, J. Dusza, P. Kun, C. Balazsi, Scripta M aterialia 66, 793 (2012)

[36] Gergely G., Sahin C.F., Göller G., Yücel Ö., Balazsi C., Microstructural and mechanical investigation of hydroxyapatite-zirkonia nanocomposites preparad by spark plasma sintering, Journal of European Ceramic Society 33 (2013) 2313-231

[37] A. Nakahira, M. Tamai, K. Eguchi, S. Nakamura, K. Yamashita, Key Eng. M at. 240-242, 551 (2003)

[38] Y. Watanabe, T. Ikoma, A. M onkawa, Y. Suetsugu, H. Yamada, J. Tanaka, J. Am. Ceram. Soc. 88, 243 (2005)

[39] Z Shen, Z. Zhao, H. Peng, M. Nygren, Nature 417, 266 (2002) 